\title{
Load Management in District Heating Systems
}

\author{
S. F. VAN DER MEULEN
}

University of Twente, P.O. Box 217, Enschede NL-7500 AE, (The Netherlands)

\section{HEATING INSTALLATIONS CONNECTED TO DISTRICT HEATING SYSTEMS}

\subsection{District heating as a heat source}

District heating is in most cases based on the availability of low-cost heat, for instance, residual heat of industrial processes such as the generation of electric power. To utilize this heat, facilities for transport, distribution and delivery must be provided. The greater part of the expenditure on district heating consists of these capital-intensive provisions. For the economic base of district heating systems it is of primary importance that the load factor of the parts of the system, related to the design power, is as large as possible.

Beside large-scale systems, generally based on cheap residual heat from industrial origins, small-scale systems can also be considered. In these systems, heat is generated by a heat pump or a small total energy installation [1]. With these systems the transport over relatively long distances can be abandoned. They can also be completed within a short time, consequently making the initial deficit smaller. Notwithstanding the higher production costs of heat, these systems can be the most economic solution in a number of cases.

In the majority of cases, district heating is a public utility delivering heat to more than one, and often to a large number of different customers. The transport medium is, as a rule, water which has almost without exception a temperature of $<100{ }^{\circ} \mathrm{C}$ at the delivery point. The characteristics of the means of production (e.g., heat pumps) can induce the application of considerably lower temperatures. Usually the supply temperature is controlled according to the outside temperature.

The heat supply mainly serves the space heating of the connected buildings. According to the current trend of better insulation of buildings, the supply of heat for the heating of tap-water is becoming increasingly im- portant. Since the demand for warm tapwater is almost independent of the season, this heat delivery can contribute considerably to the economy of the system. However, the need of a heat supply for tap-water heating means that the water supply temperature cannot decrease below $70^{\circ} \mathrm{C}$ outside the heating season. This causes relatively large distribution losses, therefore a central heatexchanger, placed in a substation and serving a separately circulated warm tap-water network is a viable alternative.

\subsection{The supply of heat as a public utility:} the connecting station

The supply point ("connecting station") is of crucial importance in the juridical as well as the technical sense. Here the supply boundary is situated and here the transfer of property of the delivered heat takes place.

The following variables describe the supply of heat (see Fig. 1):
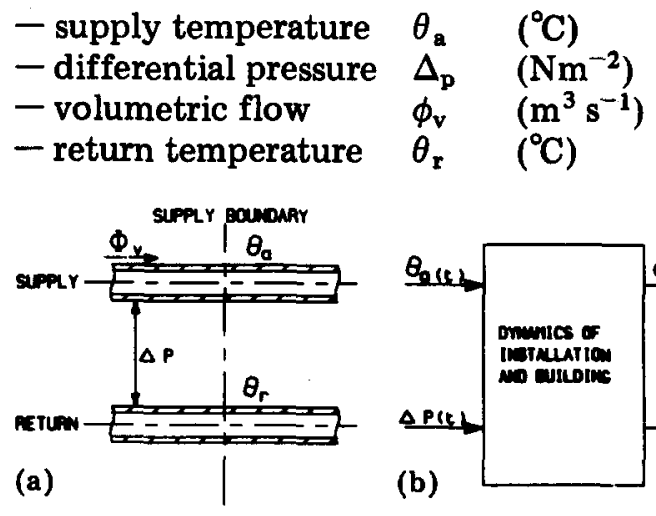

Fig. 1. (a) Variables describing heat supply. (b) Causal relations in heat supply.

Most supply situations comply with the following causal relations:

- the public utility imposes $\theta_{\mathrm{a}}$ and $\Delta_{\mathrm{p}}$ on the connected installation;

- the consumer causes $\phi_{\mathrm{v}}$ and $\theta_{\mathrm{r}}$ (i.e., the cooling $\Delta \theta=\theta_{\mathrm{a}}-\theta_{\mathrm{r}}$ ). 
The contractual responsibility of the supply company means that the values of $\theta_{\mathrm{r}}$ and $\Delta_{\mathrm{p}}$ are maintained within the contractual limits irrespective of $\phi_{\mathrm{v}}$ and $\theta_{\mathrm{x}}$ as long as these latter variables remain within their contractual boundaries. The load on the system is determined by what happens in the customer's installation.

The connecting station is the property of the supply company and it should be distinguished from the central control station ("house station") found in most larger installations. In this station the control instrumentation serving indoor climate, the heating of tap-water, etc., can be found. This forms part of the installation in the building and belongs to the property owner (see Fig. 2).

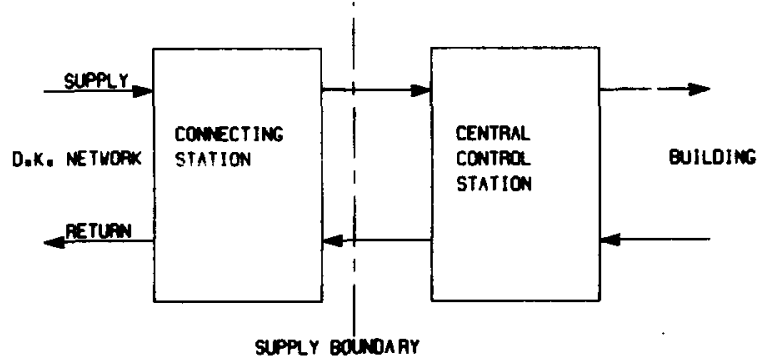

Fig. 2. Connecting station and central control station.

In the connecting station, provisions can be found such as:

- heat measurement for accounting purposes;

- control and/or limiting of $\Delta_{p}$;

- limiting of absolute pressure.

\subsection{The installations in the building and the district heating svstem}

The installations in buildings connected to district heating are not fundamentally different from individual installations with proprietary boilers. In practice however many important differences can be established. These consist mainly of the following points.

\section{Individual installation: proprietary boiler}

- Maximum power is available instantaneously, irrespective of the season.

- The energy price is almost independent of power.

- As a rule, the heating installation will be designed as a "90-70" installation for economical reasons. (Supply temperature at maximum load $90^{\circ} \mathrm{C}$, return temperature $70{ }^{\circ} \mathrm{C}$.)
- The hydraulic design is often simple and is based - certainly in small installations - on amply calculating the duty of the circulating pumps.

\section{Connection to district heating}

- The supply temperature $\theta_{\mathrm{a}}$ is controlled relative to the outdoor temperature and, particularly when no tap-water is to be heated in the installation, the available heating power is limited to a level below the design value except during the coldest days.

- The energy cost per unit of heat is strongly dependent on the power (often in a complicated way).

- In conjunction with the characteristics of the methods of production of heat, it is sometimes advantageous that "low temperature installations" be installed. (Supply temperature at design power $<90^{\circ} \mathrm{C}$.) A larger temperature difference than the customary $20^{\circ} \mathrm{C}$ is always desirable.

- Restriction of flows is always imperative and a good hydraulic design, followed by a careful adjustment of the installation is necessary.

Generally speaking, it can be stated that an installation which is connected to a district heating network cannot be merely a copy of an individual installation supplied by local boilers. The load which the installation exerts on the network depends on:

- the meteorology (the weather);

- the temperature demand (the behaviour) of the occupants; the dependency of the temperature of the time of day is especially important;

- the dynamics of the installation and, above all, of the building itself;

- the control instrumentation, its settings and programming.

It turns out that a very reproducible demand pattern is generated by these influences.

\section{An example}

In the course of current research carried out by order of VESTIN [2], the heat supply to a complex comprising 34 small houses has been investigated. These houses in Utrecht are connected to the district heating system of N.V. PEGUS. They are arranged in two building blocks with a total volume of about 


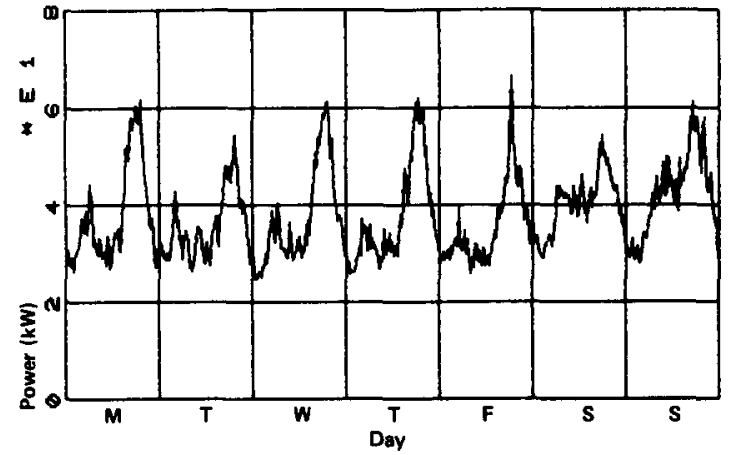

Fig. 3. Ensemble averaged heat power (12 weeks) supplied to a complex of 34 houses.

$7600 \mathrm{~m}^{3}$. The average heat transmission coefficient of the outer shell, as calculated according to the Dutch norm NEN 1068, amounts to $U=0.83 \mathrm{~W} \mathrm{~m}^{-2} \mathrm{~K}^{-1}$.

To suppress the influence of incidental meteorological circumstances, etc., the weekly heat-power functions have been averaged for 12 weeks. The result (a so-called ensemble average) is displayed in Fig. 3. The resulting demand pattern is related to the behaviour of the occupants of the buildings. This commuter district is mainly inhabited by young people, most of them employed outdoors. This causes an 'evening peak'. It is important to note that the load pattern has originated exclusively from manually controlling the thermostatic radiator valves. Other controls like clock thermostats have not been installed. Possible consequences of the use of such apparatus is discussed afterwards in Section 3.1.

\subsection{Mutual adjustment of production,} transport, distribution and the demand of heat

In district heating one must make allowance for the coupled (industrial) process, e.g., the generation of electric power. This results in the following profiles of heat supply:

- day

- week

- seasonal.

Examples:

- batchwise heat production in waste-heat boilers of steel plants;

- peak load in the generation of electric power (the results for the accompanying heat supply depend on the characteristic of the specific plant !);
- decrease in production during weekends.

On the demand side there are also similar profiles of heat demand, i.e.,

- day

- week

- seasonal.

We already referred to this situation in Section 1.3.

The difference between supply and demand must be bridged. Several courses can be taken to achieve this:

- utilization of auxiliary boilers (adjusting production to the demand);

- load management (adjusting demand to production! - the subject of this treatise);

- buffering of heat;

- allowing restricted situations of lack of power.

The utilization of auxiliary power causes relatively high (primary) energy costs. Buffering of heat can take place centrally (next to the production centre) or be decentralized (even in the consumers building). The buffering capacity of the network can also be exploited as far as (fast) temperature changes are allowed. The economic yield of buffering is proportional to the number of load/unload cycles a buffer passes through during a season.

Small-scale buffering (by the consumers) is almost never economically justifiable [3].

For auxiliary boilers as well as buffering facilities, it is advantageous when they are placed in the periphery of the supply district. In combination with a good design this enlarges the load factor of the network. The eventual decision about the location has to be part of the optimization of the design of the whole system.

In the collection of measures as a whole, load management has its own place. In this case, use is made of the opportunity which exists on the users' side of the supply boundary to adjust the demand proportionally to the production. This procedure requires a perhaps unconventional approach which will be dealt with in the next Sections.

\section{LOAD MANAGEMENT}

\subsection{Optimization of heat supply}

The ultimate objective of load management can be described as follows: 
To effectuate the heat supply in such a way that the attainment and the maintaining of the intended indoor climate will be realized with minimal total cost.

This definition, in fact, points to optimization of the whole system. This system consists of the combination of the whole district heating system and the connected buildings, including the installations. It is important to stress that the ultimate objective of district heating is to maintain a suitable indoor climate in the connected buildings and not to supply heat. The heat supplied to a building can be considered as a control variable, needed to control the indoor climate.

In the optimization problem, distinction must be made between the optimization of the design and the optimization of the operation of the system.

\section{Optimization of the design}

A consequence of the optimization of the design has already been indicated in Section 1.3. The characteristics (work-lines) of the installations in the buildings and the district heating system have to be matched. This can lead, for instance, to low-temperature installations in the buildings. It is generally desirable to design building installations with high temperature difference (low return temperature), limiting in this way the flows in transport and distribution.

\section{Optimization of the operation}

Let us explain first that, in this context, by "operation" we understand the handling of the installations in the buildings and of the district heating system in their mutual relationship. Optimal operation can be based on the optimization methods of control theory. The fundamentals of these methods are not discussed in this treatise, they can be found in textbooks such as ref. 4 .

For the total system, as defined before, a cost function $f$ can be set up:

$f\left(x_{1} \ldots x_{n}, u_{1} \ldots u_{m}\right)$ (guilders/s)

This cost function is expressed in the state variables $x_{1} \ldots x_{n}$ and the control variables $u_{1} \ldots u_{m}$. Both types of variables are time functions; the state variables describe, simply stated, the dynamic behaviour of the system. The system is controlled by applying the control variables $u_{1} \ldots u_{m}$. Optimal control of the system during a time $T$ leads to minimization of

$F=\int_{0}^{T} f\left(x_{1} \ldots x_{n}, u_{1} \ldots u_{m}\right) \mathrm{d} t \quad$ (guilders)

In a problem like this $F$ can be expressed in monetary terms. The total cost $F$ over the time $T$ will attain its absolute minimum by optimal control of the system. Remember that the state of the system is not only influenced by the control variables $u_{1} \ldots u_{m}$ but also by a number of disturbances $z_{1} \ldots z_{k}$. This optimal control must be exercised within the limits of a number of constraints.

The constraints can generally be classified in the following way:

- constraints imposed on $x_{1} \ldots x_{n}$ and $u_{1} \ldots u_{m}$ in relation to constructional limitations (maxima for temperatures, flows, powers; negative powers are not possible without accumulation of heat, etc.);

- the indoor climate of the connected buildings must fulfil specified requirements (within certain margins!);

- constraints arising from the industrial process coupled with the heat production.

It is important to recognize that the last two constraints are time-dependent; this has in fact already been stated in Section 1.4.

A general solution for the optimal control problem is in fact beyond reach for practical purposes. In practice simplified models must be used. The cost functions are only approximately known and the disturbances must often be estimated. A feasible approach has to restrict itself to a small number of state variables and usage of relatively simple instrumentation and algorithms. In this way one can only approximate optimal control. This fact is indicated by usage of the term "suboptimal control". Often only part of the system is involved in the control operation. Nevertheless it is part of a larger system and this must always be borne in mind. We shall treat load management in district heating systems from this aspect.

\subsection{Load management as partial optimization}

Load management can be considered as partial optimization because by definition we confine ourselves to control variables working on the connecting station and the installations in the building. This approach has the opportunity to be successful because 
this subsystem exchanges relatively little information with the rest of the system. However, control of each subsystem of a large system only then can serve the optimal control of the whole system when the signals which the subsystems exchange vary in the same way as in the case of optimization of the whole system.

Although the subsystem "building plus installation" exchanges little information with the rest of the system, this information is of vital importance for optimal operation of the whole system and it must be handled consequently.

The most important state variables $x_{i}$ in load management are:

- the temperatures in the heating installation; - the temperatures of the building construction (walls, floors, etc.);

- the air temperatures in the apartments.

These state variables describe the energy storage in the pertaining elements of the system.

As control variables $u_{j}$ the following can be considered:

- flows;

- supply temperatures in the installation.

As disturbances $z_{k}$ the following can apply:

- outdoor temperature;

- wind velocity;

- (global) irradiance.

The contractually agreed supply temperature, the maximal flow and the minimal allowable temperature difference act as constraints at all times. The room temperature constraints are related to the comfort temperature inside the building [5]. This should comply within prescribed margins with the time function desired by the occupants of the building.

To fulfil the condition that load management functions as a partial optimization in accordance with the optimization of the whole system, the cost function should also be based on state variables elsewhere in the system, or at least be correlated with them. It will turn out in practice that this condition is often not met, with harmful consequences.

\subsection{Application potential of load management}

It has already been mentioned in Section 1.4. that a temporary decrease in the heat supply does not meet objections if the indoor climate does not move outside the comfort limits. This is made possible by the storage of heat in the construction of the building. Decisive are the characteristic times of the thermal dynamic behaviour of the building. These are a measure for the ratio between the heat accumulated in the mass of the building and the thermal power needed to maintain the indoor temperature.

Load management therefore has the largest potential in:

- larger buildings, especially those with a large constructional mass;

- well-insulated buildings.

Owing to the increased insulation level also in the case of small capacity connections, load management is at present a practical option (Sections 3.1 and 3.2).

In optimization it is necessary to determine the cost function and this is a very complicated matter for the district-heating system as a whole. Not only the characteristics of the source of production but also the costs of pumping energy, heat losses etc., have to be taken into account. In practice one has to reduce the cost function to a simple scheme and at any rate this scheme has to reflect two levels of production cost of heat:

- the price of residual heat;

- the price of heat generated by auxiliary boilers.

It is not uncommon for these prices to differ by a factor of 3 or 4 . The power level above which heat must be generated by auxiliary plant is not constant. In relation to the industrial process from which the residual heat is extracted, it will be a time function which has to be entered in the optimization process. The above-mentioned large difference in cost forms a solid base for the viability of load management in district heating systems.

Furthermore, we call your attention to the fact that in suboptimally controlled systems the peak loads are relatively smaller ("peak shaving" by load management). This enables design of the district heating system with closer tolerances, thus enlarging the load factor and the coincidence factor, which tends to decrease investments and heat losses.

\subsection{Instrumentation for load management}

As already explained in Section 1.3, the occupant of the building determines the 
power demand. He does so by setting the control of his installation according to his wishes for the indoor climate. In larger buildings this will be the central control station which translates the demands for an indoor climate into a heat power demand. In small installations one will find simple controls such as:

- room thermostats (perhaps programmable, i.e., clock thermostats)

- thermostatic radiator valves.

The thus created heat demand will be handled by the connecting station, specifically through the functions:

- limiting of flow,

- limiting of return temperature, and

- accounting heat measurement.

To a certain extent this structure already exerts a primitive kind of load management! The thermostats in the installation prevent unnecessary consumption of heat and the limiting functions in the connection station keep the load on the network within the contractual limits. However, as we shall see, this 'load management' is primitive, especially since some fundamental functions of optimization by load management are not incorporated. The following minimum number of functions are of primary importance:

- recording beforehand of the required indoor climate, especially the room temperature as a function of time;

- passing on of the parameters which make possible an approximation of the cost function $f\left(x_{1} \ldots x_{m}, u_{1} \ldots u_{m}\right)$ (Section 2.1);

- an optimization algorithm (a realization of a computational procedure).

Irrespective of the constructional details of the instrumentation of the connecting station and of the installations of the building, the above-mentioned functions must have been realized. On behalf of the optimization algorithm there must be at least some passing of information between the means of production, the connecting station and the control of the installations in the building at the other side.

\subsection{Cost structure and tariff structure}

A direct relationship exists between the tariff structure and the cost resulting for the consumer from a certain heat demand pattern. It is important in this context to mention the discrepancy between cost structure and tariff structure which can generally be observed.

This discrepancy is twofold:

(1) The cost structure of district heating implies a relatively large overhead. In the usual tariffs the consumption-dependent part (variable part) is the larger one, which is contrary to the cost structure.

(2) In the variable part of the tariff there is usually no allowance made for the large differences in production costs between base load and peak load (Section 2.3).

By using this method the usual tariff structures cannot be an instrument for the optimization of the operation of district heating systems. In accordance with the explanation in Section 2.2 for that purpose the tariff structure should reflect the cost structure.

This statement can be made irrespective of the eventual technical design of the accounting measurement upon which the application of the tariff is based. The cost of the accounting measurement should of course be included in the overall cost of heat supply.

\section{PRACTICAL EXAMPLES}

The heating market in the Netherlands is mainly covered by gas-fired central heating systems. The customer on a district heating system is apt to compare facilities, tariffs, etc. He expects the same controls and automation as in the case of individual central heating. Under this atmosphere of competition some developments in the field of load management are going on. In this Section they are discussed by way of illustration of the general treatment of the subject.

\subsection{The classical optimizing thermostat}

As part of the research, already mentioned in Section 1.3, the heat balances of the houses concerned have been deeply investigated. For this purpose about 100 variables were registrated during the heating season 1984 . 1985. (Temperatures and flows in the substation and in the connecting stations; room temperatures; meteorology). The thermal dynamic behaviour of the buildings was modelled (the method has been described in 
ref. 6). The measurements enabled us to verify this model and gave an insight into the behaviour of the occupants.

To save energy, most people turn down their thermostatic radiator valves during the night and during working hours. The demanded room temperature profile can be closely approximated by Fig. 4 . The resulting load pattern has already been displayed in Fig. 3.

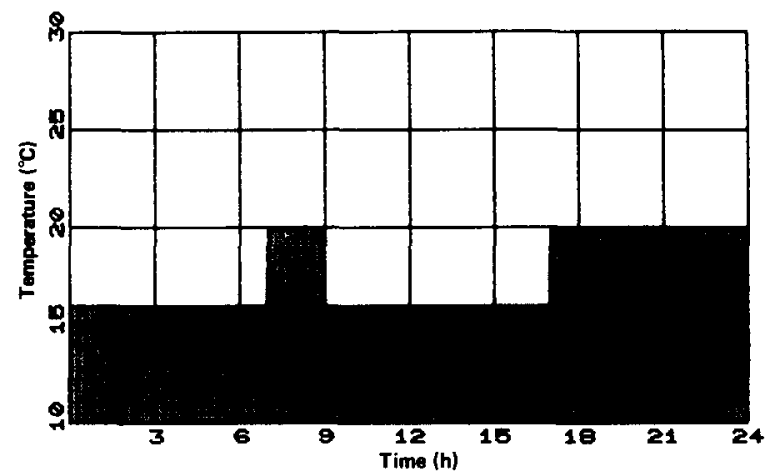

Fig. 4. Model for demanded room temperature for average occupant.

The use of the programmable thermostats is becoming widespread and they are also being applied in the installations which are connected to district heating systems. So the question has been posed - what consequences the use of a classical optimizing thermostat at each connection of the test object would have? It is known that such a thermostat minimizes the energy consumption by starting the heating-up process with maximum power at such a point that the room temperature of $20{ }^{\circ} \mathrm{C}$ is reached at the correct moment in time.

\subsection{The integrated connecting station}

Within the scope of the aforementioned research project concerning the optimal supply of heat to small housing [2] a proposal has been put forward for a different layout of the connecting station. In this so-called integrated connecting station the measurement and control functions around the delivery boundary, including room temperature control of the connected house, are assembled in one integrated set-up. As many of the functions as possible are realized by application of microelectronics, thus minimizing the number of vulnerable mechanical parts (Fig. 5).

We discuss here the results for one day. The meteorological variables for January 15, (a cold day) have been applied as input for the model. The internal heat production has been estimated mainly on the basis of the known supply of electrical energy to the complex and the statistics of the consumption of electrical energy in private households. We compared two situations:

(1) maintaining a constant room temperature of $20^{\circ} \mathrm{C}$.

(2) applying the classical optimizing thermostat in all houses with a heating profile according to Fig. 4.

The results have been summarized in Table 1. It can be seen from the second column that the net energy saving for the complex amounts to $856 \mathrm{MJ}$. The resulting heat demand function has been reproduced in Fig. 6. The very large power peaks during the morning and evening have to be covered largely by expensive heat generated in auxiliary boilers.

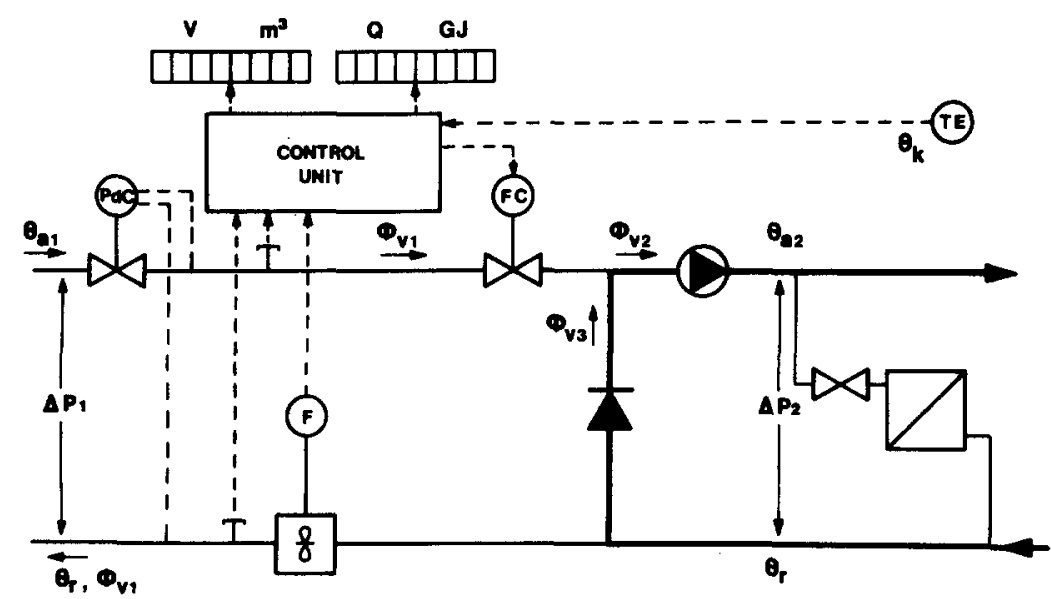

Fig. 5. The integrated connecting station. 
TABLE 1

Comparison of the classical optimizing thermostat and suboptimal load management

\begin{tabular}{llll}
\hline & $\begin{array}{l}\text { Continuous } \\
\text { heating } \\
\text { at } 20^{\circ} \mathrm{C}\end{array}$ & $\begin{array}{l}\text { Classical } \\
\text { optimizing } \\
\text { thermostat }\end{array}$ & $\begin{array}{l}\text { Suboptimal } \\
\text { load management } \\
\text { (integrated connection } \\
\text { station) }\end{array}$ \\
\hline Max. heat power $\boldsymbol{P}_{\max }$ & $102.0 \mathrm{~kW}$ & $130.0 \mathrm{~kW}$ \\
Average heat power $\boldsymbol{P}_{\text {aver }}$ & $87.9 \mathrm{~kW}$ & $177.6 \mathrm{~kW}$ & $80.0 \mathrm{~kW}$ \\
Ratio $\boldsymbol{P}_{\text {max }} / \boldsymbol{P}_{\text {aver }}$ & 1.16 & $78.0 \mathrm{~kW}$ & 1.63 \\
Energy supply $/ 24$ hours & $7595 \mathrm{MJ}$ & 2.28 & $6912 \mathrm{MJ}$ \\
$\begin{array}{l}\text { Energy supplied with } \\
P>130 \mathrm{~kW}\end{array}$ & - & $6739 \mathrm{MJ}$ & - \\
$\begin{array}{l}\text { Savings on supplied } \\
\text { energy, compared with }\end{array}$ & - & $890 \mathrm{MJ}$ & $683 \mathrm{MJ}$ \\
continuous heating at $20^{\circ} \mathrm{C}$ & & $856 \mathrm{MJ}$ & \\
\hline
\end{tabular}

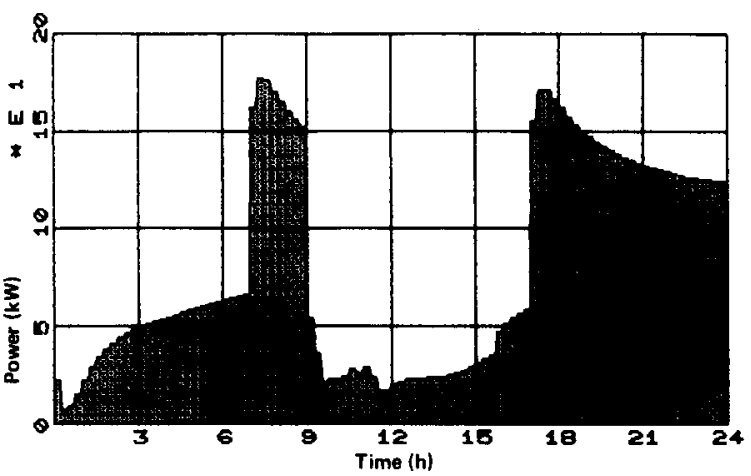

Fig. 6. Heat demand in the case of universal application of conventional optimizing thermostats.

According to the tariff a fixed price per GJ is charged. The classical optimizing thermostat leads in the case of this tariff to (maximum) savings for the customer, but brings about considerably higher costs for the public utility. Partial optimization in this way does not fit into total optimization. The crucial point here is the cost function upon which the partial optimization is based. The cost function for the customer is derived from the tariff and as already stated there is a large discrepancy in this case between the tariff structure and the cost structure.

The investment in this set-up is not to exceed the investment in the instrumentation it replaces.

The primary goals of this arrangement are: - provision of an infrastructure for load management;

- better measurement of heat for accounting purposes;

- provision of a good and programmable room-temperature controller to the customer.
The measurement of heat by way of the integrated connecting station has been described elsewhere [7]. The facilities for load management may be demonstrated by comparison with the situation already described in Section 3.1.

- The occupant has programmed the integrated connecting station according to the temperature profile of Fig. 4.

- The district heating company assigned a power level of $130 \mathrm{~kW}$ for the whole section above which auxiliary power has to be supplied.

- An algorithm in the integrated connecting station determines a suboptimal power profile which never exceeds the level of 130 $\mathrm{kW}$ and assures a room temperature not under the function of Fig. 4.

This situation has been simulated again with the same model and the same external conditions as in Section 3.1. The results are shown in Fig. 7 and Table 1 (column 3). In comparison with the application of the

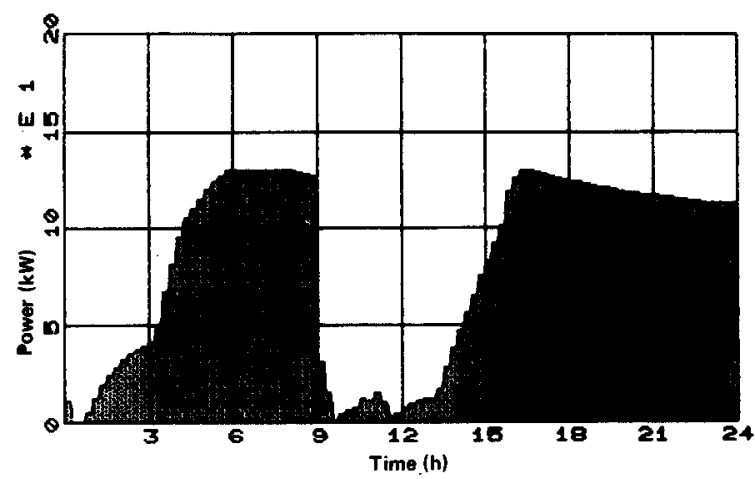

Fig. 7. Heat demand in the case of load management by the integrated connecting station. 
classical optimizing thermostat, $173 \mathrm{MJ}$ more heat has to be supplied. However the primary energy demand is far less than in the former case. This is due to the avoidance of heat supply from the auxiliary boilers.

In the Utrecht case it is estimated that during the whole heating season this simple suboptimal control can save at least $10 \%$ of primary energy. Prototypes of the integrated connecting station have been placed in a field test in Utrecht and Enschede. They operate according to expectation and are accepted by the customers. It is expected that manufacturing of integrated connecting stations in larger quantities will lead to a lower price than the sum of the parts they replace (heat meter; programmable thermostat, etc.).

With regard to the implementation of load management by means of the integrated connecting station, it can be further stated that:

- To reward load management (or to share the profits), the tariff structure must be changed in most cases. The technical design can be based for instance on a meter with two counters, one for the 'low' tariff and one for the 'high' tariff.

- Some kind of communication between the production centre and the connecting station is needed. This can be shaped as a low-cost data-communication channel for which proposed standards are already available. As such may be mentioned channel $D$ of ISDN (Integrated Services Digital Network) according to Comité Consultatif International de Télégraphie et Téléphonie.

\subsection{Collective night decrease in an apartment building}

In Section 3.2, load management is directly involved in the room-temperature control loop. From measurements on apartment buildings in Utrecht it became evident that load management can also be attained by control of the supply temperature of the building as a whole. The building is characterized by the following data:

- the building is of heavy construction (prefabricated concrete wall elements);

- it contains 116 apartments;

- outside temperature-coupled control of the supply temperature to the apartments;

- control of the room temperatures by thermostatic radiator valves;

- connected nominal load c. $1030 \mathrm{~kW}$.
It turned out that a decrease of the supply temperature of about $20^{\circ} \mathrm{C}$ during the period 24:00-06:30 indeed yields a moderate energy saving of approx. 5\%, in spite of the presence of the thermostatic radiator valves. The mechanism of this phenomenon can be described by a simple model. The proportional band and hysteresis of the thermostatic radiator valves cause a lower room temperature during night hours and the amount of accumulated heat decreases. In the morning a large peak load develops, which must mainly be covered by the auxiliary boilers. Therefore also load management is appropriate. As one connecting station serves a large number of apartments in this case, the relative cost of the additional instrumentation will be low.

\subsection{Bivalent connections}

Load management as described in Sections 3.2 and 3.3 is based on heat accumulation in the building construction. It is possible, in this way, to spread the supply of heat over some hours. However, all heat has to be supplied by the district heating network. An improvement of the load pattern over longer time spans can be accomplished by operation of a means of heat production locally within the connected installation. Connections equipped with this facility are referred to as bivalent connections.

For reasons of economy in the first place larger connections can be considered. $\left(P_{\max }>\right.$ $500 \mathrm{~kW}$ thermal). The District Heating Utility of Breda (ENWA) realized since 1985 a number of bivalent connections of larger installations (schools, greenhouses, industrial buildings). The maximal contracted load of the district heating network has been restricted to between $30 \%$ and $50 \%$ of the maximum installation load. The instrumentation has been set up for the time being with conventional control instruments.

The potentialities of this type of connection have not been fully explored yet. Load management in the sense of Section 2 has not been practised; however the configuration is perfectly suited for functioning in optimizing of the operation of the district heating network as a whole.

The first experiences show that the local boilers have only been in service during cold periods. Only $5 \%-10 \%$ of the yearly heat consumption has been generated locally. 
The load factor related to the maximum load of the connection has about doubled in most cases. In fact, part of the auxiliary boilers of the district heating system has been transferred to a strategic position in the periphery of the network.

\section{CONCLUSIONS AND RECOMMENDATIONS}

By connecting a building to a district heating system, the building, its installations and the district heating system form one coherent system with many internal interactions. In order that this whole system functions in the most economic way, the installation in the building cannot be a copy of a single isolated installation with a proprietary boiler. This applies to the dimensioning as well as the operation of the installation. A number of points to which special attention should be paid are given in the following paragraphs.

\subsection{Optimal dimensioning of the installations in buildings}

The design and dimensioning of the heating installations and of the district heating system should be matched. This applies specially to: - installation load and insulation level of the building: above a certain insulation level the "Law of Diminishing Returns" makes further insulation less profitable than investment in connection to a district heating system;

- the dimensioning of the distribution network: overdimensioning of the distribution network should be avoided as much as possible;

- the working lines of the installation and of the district heating system should match, and should together be optimized for lowest total cost of heating.

These ideals will almost never be realized at the same time. However housing estates with an order of magnitude of one hundred houses or more are often designed as a whole. Most of the above-mentioned recommendations are therefore quite practical in the periphery of the district heating network. Also, the tariff system (Section 4.5) should encourage application of the above-mentioned design guidelines.

\subsection{Load management as a control problem}

The intended effect, that is "room heating for minimal costs", requires optimal control of the whole system, consisting of district heating system, connected installations and the buildings together. In practice this means: - the control of the district heating system and of the installations in the buildings cannot be effected independently;

- this implies that information must be transferred across the supply boundary.

One problem to be solved in the near future is how to coordinate the control of the installations in the buildings and of the district heating system.

\subsection{Transfer of information across the supply boundary}

The aforementioned information transfer has to be specified:

- the nature of the information, i.e., the choice of the signals;

- the technical design, such as the choice of the information carrier.

It is desirable to join the standardization which is taking shape in the field of low-cost digital communication, also the potentialities of ISDN should be observed.

The cost function, which plays a central role in the optimization of operation, will be related to the amount of supplied heat. Therefore special attention must be paid to the role of the accountable measurement of the supplied heat.

\subsection{Development of instrumentation}

The set-up of instrumentation for measurement and control in an installation which is connected to a district heating system, is at present too much a derivative of common practice for individual installations. It is however desirable to modify and complement the actual sales programmes of control instrumentation in such a way that load management becomes feasible.

\subsection{Contractual aspects}

From an economic point of view, it is desirable to let the customer contribute as much as possible to the cost of heat supply in accordance with the real cost structure. The contracts and the tariff should reflect this. 
(1) Overheads should be in accordance with the investments in the district heating system.

(2) Variable prices to be arranged for supplied heat, relative to the actual production costs.

The first point is practical as far as the charged overhead corresponds with the investments and expenses which the customer does not need to bear because of his connection to the district heating system. This can go further than superficially may be thought. Not only the boiler installation, repair and replacement, but also the investment in insulation (above a certain level) should be considered.

The second point implies modifying the consumption-dependent part of the tariff. This requires coupling of the accountable measurement and the information transfer mentioned in Section 4.3. From a technical viewpoint this is a practical proposition.

The situation thus arising should be covered by the contract between supplier and consumer of the heat. The legal terms of the modification of the obligation to deliver heat, the status of the information transfer and the rights and duties of both parties with respect to the instrumentation should be settled.

\section{REFERENCES}

$1 \mathrm{~K}$. Hein and R. Lotz, Blockheizkraftwerke - ja, aber richtig, (Modular cogeneration heating plants - yes, but properly), Fernwarme International, 15 (1986).

2 Optimalisatie van warmtelevering aan kleine woonhuisaansluitingen; metingen en modellen, (Optimization of heat supply to small district heating connections; measurements and models), Publ.VES 86/31 VESTIN, Arnhem, The Netherlands, 1986.

3 U. Kaier, Energiespeicherung, Brennst. wärme kraft, 32 (4) (1980) 163 - 165.

$4 \mathrm{H}$. Kwakernaak and R. Sivan, Linear Optimal Control Systems, John Wiley, New York, 1972.

5 P. O. Fanger, Thermal Comfort, McGraw-Hill, New York, 1972.

6 G. G. J. Achterbosch, P. P. G. de Jong, C. E. Krist-Spit, S. F. van der Meulen and J. F. C. Verberne, The development of a convenient thermal dynamic building model, Energy Build., 8 (1985) 183 - 196.

7 S. F. van der Meulen and J. F. C. Verbene, Impulse-value, flow threshold and dynamic range in small heat meters, Fernwarme International, 14 (1985) 219 - 223. 